\title{
Triptolide Resistance Was Prevented by Metformin Co-Treatment Under Increased Growth Hormone Signaling Conditions in MDA-MB-231 Cells ${ }^{+}$
}

\author{
Gizat Rakhmatula, Pinar Obakan Yerlikaya, Elif Damla Arisan and Ajda Coker Gurkan * \\ Department of Molecular Biology and Genetics, Istanbul Kultur University, Atakoy Campus, 34156 Istanbul, \\ Turkey; gunch.kz@gmail.com (G.R.); p.obakan@iku.edu.tr (P.O.Y.); d.arisan@iku.edu.tr (E.D.A.) \\ * Correspondence: a.coker@iku.edu.tr; Tel.: +90-212-498-4567 \\ + Presented at the 3rd International conference on Natural Products for Cancer Prevention and Therapy, \\ Kayseri, Turkey, 18-20 December 2019.
}

Published: 25 December 2019

\begin{abstract}
Breast cancer is identified as the most common cancer among women and the leading cause of cancer-related deaths. Increased expression of growth hormone $(\mathrm{GH})$ has been found to cause cell growth, drug resistance and invasion-metastasis in breast cancer. Triptolide is a diterpenoid isolated from Tripterygium wilfordii with anti-cancer activity. Our data showed that GH overexpressing MDA-MB-231 cells exhibited a resistance mechanism against tripitolide treatment when compared to wild type MDA-MB-231 cells. To overcome the resistance, we combined triptolide with metformin, an anti-diabetic agent with anti-tumorigenic effect and a potential adjuvant in the management of breast cancer. Our findings indicated that $\mathrm{GH}+$ cells exhibited increased cell viability loss, mitochondrial membrane potential loss and apoptotic cell death with metformin co-treatment. In addition, colony sizes were significantly decreased due to combined treatment. Autophagy is a process of cellular self-degradation during which macromolecules, damaged organelles are delivered to the lysosome in order to control energy level under stressed conditions. Cells can control proliferation or apoptosis by changing the level of autophagy, it has been proposed as a chemoresistance mechanism. Our data showed that there was no significant change in the autophagy induction in MDA-MB-231 wt and GH+ cells treated with triptolide and metformin.
\end{abstract}

Keywords: growth hormone; breast cancer; metformin; triptolide; autophagy

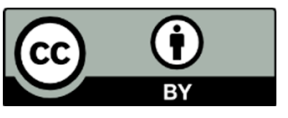

(C) 2019 by the authors. Licensee MDPI, Basel, Switzerland. This article is an open access article distributed under the terms and conditions of the Creative Commons Attribution (CC BY) license (http://creativecommons.org/licenses/by/4.0/). 